\title{
Política y Sociedad
}

ISSN: $1130-8001$

ISSN-e: $1988-3129$

Muñoz Comet, J. (2016): Inmigración y empleo en España. De la expansión a la crisis económica, Madrid, Centro de Investigaciones Sociológicas, 195 pp.

La investigación de Muñoz Comet sobre la participación laboral de la población extranjera en España se plantea varias preguntas y tiene la virtud de ofrecer para ellas un conjunto bien fundamentado de respuestas.

El estudio abarca la primera década del presente siglo, un periodo donde tienen lugar dos procesos de gran relevancia (p.15). Uno es demográfico, la intensa llegada de inmigrantes y su vinculación con los rasgos ocupacionales del crecimiento económico español asociado al boom inmobiliario. El otro es económico, el final abrupto de dicha fase expansiva con la llegada en 2008 de la denominada Gran Recesión, que aún caracteriza el panorama social y laboral de nuestro país. La presencia de inmigrantes se frena entonces y son, precisamente, los efectos laborales de la recesión los que centran este trabajo. Para ello, se propone un marco analítico con base en una preocupación de calado para las ciencias sociales, la que tiene que ver con la desigualdad (o, como se denomina a menudo en el texto, la brecha o desventaja) que afrontan los extranjeros en el mercado laboral del país de acogida y, en particular, con los factores que la explican.

Tanto el planteamiento como los resultados de este trabajo conducen a señalar las limitaciones explicativas de los dos enfoques teóricos que protagonizan el estudio de las diferencias entre inmigrantes y nativos y sus causas. Para la teoría de la asimilación, la desigualdad de oportunidades laborales que sufren los extranjeros tiene en todo caso carácter temporal, se sitúa en los primeros años y desaparece en la medida en que el inmigrante refuerza su capital humano, adapta sus características personales como trabajador al mercado laboral de acogida (idioma, experiencia sectorial y en la empresa). Desde la teoría de la segmentación, la desigualdad no tiene carácter coyuntural. Los mercados de trabajo compartimentan los tipos y condiciones de empleo. La movilidad desde el segmento secundario (el de las ocupaciones inestables y las condiciones precarias) al primario (el de los puestos de trabajo estables y mejor remunerados) es, como mínimo, poco frecuente. La mayor parte de la población inmigrante ingresa en el mercado laboral a través de ocupaciones del segundo segmento (lo que el autor denomina en ocasiones la "puerta de atrás"). Este hecho condiciona las trayectorias de los inmigrantes, desigualando su situación y sus oportunidades, con independencia del paso del tiempo y de sus características en lo que a capital humano se refiere. 
En España, la participación laboral de extranjeros y nacionales presenta diferencias. Pero, ¿qué provoca estas diferencias? ¿Tienen que ver con la preparación y la experiencia con la que llegan $\mathrm{y}$, por tanto, tienden o pueden desaparecer con el tiempo de residencia? ¿Tienen que ver con el tipo y condiciones de empleo a los que se accede y con el hecho de que la segmentación del mercado laboral dificulte de facto la movilidad ascendente? ¿Influyen de la misma forma el capital humano o el estatus y la trayectoria ocupacional en un contexto económico expansivo que en uno recesivo?

Estas son las preguntas que guían la indagación de Muñoz Comet. Pero, por encima de estas, o aunándolas, se plantea la verdadera pregunta que preside su trabajo. Desde un punto de vista formal, se trata de dilucidar si las respuestas basadas en uno y otro enfoque (el de la asimilación y el de la segmentación) son suficientes como explicaciones a las desventajas laborales que afectan a los inmigrantes. Desde un punto de vista más social y, por eso mismo, igual de sociológico, la cuestión es si la nacionalidad es o no un factor de desigualdad en el mercado de trabajo.

Los hallazgos se obtienen tras un exhaustivo análisis de datos procedentes del fichero de flujos de la EPA que permite seguir la situación laboral de un mismo individuo a lo largo de seis ediciones trimestrales de la encuesta (año y medio). Estos datos se enriquecen, además, mediante su minuciosa fusión con los datos trasversales (procedentes de cada encuesta trimestral), a fin de incorporar a los análisis un conjunto de variables que no están presentes en el citado fichero de flujos. El autor describe con rigor y claridad los rasgos metodológicos de su investigación, sin renunciar a señalar en varios pasajes del texto algunas limitaciones de la fuente elegida y del procesamiento de los datos que esta permite efectuar. Además, cada capítulo dedicado a la presentación de resultados ofrece una clarificadora descripción de los datos, variables y técnicas descriptivas y multivariantes empleadas.

En el mercado laboral español existe una brecha entre trabajadores nativos y extranjeros al inicio del periodo estudiado que persiste, aunque cambia, tras la irrupción de la recesión económica.

La investigación trata de conocer cuáles son los factores que favorecen el desempleo (aumentando el riesgo de perder el puesto de trabajo); cuáles los que contribuyen a la reinserción laboral (aumentando la probabilidad de volver a ocuparse); y cuáles los que mejoran dicha reinserción (permitiendo volver a la ocupación en un puesto mejor que el ocupado anteriormente). Asimismo, se quiere saber en qué medida la influencia de estos factores acusa la influencia del cambio de ciclo económico, del paso de una fase expansiva a una recesiva.

En contra de lo sostenido por la teoría de la asimilación, los factores relacionados con el capital humano y, en particular, el tiempo de permanencia en el mercado laboral (expresado en número de años de residencia) no influyen tanto en las oportunidades laborales como las características del empleo al que se accede. De forma particular, la contratación temporal y la ocupación en puestos de "segunda categoría" contribuyen a explicar mejor las entradas y salidas del desempleo que el nivel educativo o la antigüedad en el puesto o la empresa. A partir de aquí, el trabajo establece dos importantes constataciones. 
En primer lugar, que la llegada de la recesión económica a partir de 2008 hace aumentar la influencia de los factores individuales, los asociados al capital humano, aunque este incremento es aún mayor para los factores relacionados con la trayectoria y el estatus profesional. La mayor inestabilidad que afrontan los extranjeros tras la llegada de la crisis se comprende mejor desde el enfoque de la segmentación que afirma que el acceso y permanencia en las ocupaciones más inestables merma las oportunidades laborales. La mayor parte de la población inmigrante accede al mercado de trabajo español en posiciones de menor categoría y que, en muchos casos, no se corresponden con el nivel de cualificación que se porta. La segmentación de nuestro mercado laboral los sitúa así en desventaja y más vulnerables ante un cambio de ciclo económico. Para los extranjeros, las desventajas iniciales han pasado a ser mayores con la crisis.

En segundo lugar, y sin perjuicio de lo anterior, Muñoz Comet llama la atención sobre el hecho de que el conjunto de los factores relevantes para los enfoques de la asimilación y de la segmentación no logra explicar por completo la brecha que se detecta con anterioridad a la crisis económica. Por tanto, la nacionalidad importa, ejerce una influencia neta. Sería independiente del capital humano que uno acumule a lo largo de su permanencia en el mercado laboral; e incluso de la trayectoria y categoría alcanzadas. Una vez medida la influencia que ejercen capital humano y condiciones ocupacionales, la desigualdad restante revelería que la nacionalidad influye sobre las oportunidades de empleo.

El investigador no esconde que parte de esta desigualdad pueda explicarse por limitaciones del diseño como, por ejemplo, que algunos factores potencialmente relevantes no se encuentren medidos por la EPA. Pero, con independencia de eso, el autor se alinea con la hipótesis de que tener otra nacionalidad implica el pago de un peaje o penalización en nuestro mercado laboral. Los extranjeros afrontan diferentes oportunidades laborales con independencia de sus rasgos sociodemográficos (edad, género, región de residencia en España) o relacionados con el capital humano (nivel educativo, experiencia profesional). El de la existencia de ethnic penalties (p. 168) constituye un enfoque sobre el que se hace una breve pero interesante revisión de aportaciones en el capítulo final. Con ellas se invita a comprender que la brecha entre ambos grupos exista y persista con el paso del tiempo por el hecho de que las estrategias de inserción de los inmigrantes difieren (o se ven forzadas a diferir) de la de los nacionales.

Sin duda, constituye una de las pocas limitaciones de este trabajo el que las implicaciones derivadas de esta perspectiva no hayan desempeñado un papel más relevante en las decisiones de investigación. Pero, ante las dificultades que eso hubiera entrañado desde el punto de vista metodológico, que no se nos deben escapar, debe saludarse el hecho de que al autor no solo no rehúya, sino que invite con sus conclusiones a nuevas aportaciones que se abran en esa dirección.

Federico Pozo Cuevas

Universidad Pablo de Olavide de

Sevilla

fpozcue@upo.es 